\title{
AVALIAÇÃO EDUCATIVA: PRODUÇÃO DE SENTIDOS COM VALOR DE FORMAÇÃO
}

\author{
José DiAs SoBrinho*
}

Recebido: 12/12/2007

Aprovado: 20/01/2008

\begin{abstract}
*Professor do Programa de Pós-Graduação em Educação da UNISO (Universidade de Sorocaba); Professor titular aposentado da UNICAMP; Editor da Revista Avaliação; Autor de diversos trabalhos sobre educação superior e avaliação da educação superior. Seus últimos livros são: "Universidade e Avaliação. Entre a ética e o mercado" (Insular, 2002), "Avaliação. Políticas educacionais e reformas da educação superior" (Cortez, 2003) e "Dilemas da Educação Superior no mundo globalizado. Sociedade do conhecimento ou economia do conhecimento? (Casa do Psicólogo, 2005).
\end{abstract}

Resumo: Este artigo apresenta a avaliação como uma produção de sentidos, especialmente sobre as finalidades essenciais da educação. É prática social polissêmica que não se limita ao conhecimento e ao processo ensino-aprendizagem. Busca compreender os significados dos fenômenos educativos, inclusive as questões relativas à autonomia pessoal e à vida social e pública do sujeito da educação e sua participação na construção da sociedade democrática. Atribui especial ênfase à avaliação dinâmica e participativa e discute as relações entre avaliação e regulação.

Palavras-chave: Avaliação. Educação Superior. Produção de sentidos. Avaliação Estática. Avaliação Dinâmica. Avaliação e Regulação.

\author{
EDUCATIONAL EVALUATION: THE PRODUCTION \\ OF MEANING WITH EDUCATIONAL VALUE.
}

\begin{abstract}
This article presents evaluation as a production of meaning, especially the meaning of the essential purposes of education. It is a social polisemic practice that does not limit itself to knowledge and the teaching-learning process. It tries to comprehend the meanings of the educational phenomenon, including the issues relative to personal autonomy and to the social and public life of the subject of education and his participation in the construction of a democratic society. Special emphasis is attributed to the dynamic and participative evaluation and to the discussion of the relation between evaluation and regulation.
\end{abstract}

Keywords: Evaluation. Higher education. Production of meanings. Statistical evaluation. Dynamic evaluation. Evaluation and regulation.

\section{Introdução}

A avaliação educativa deve ser uma produção de sentidos sobre o cumprimento, pelos sistemas e pelas instituições, das finalidades de formação de cidadãos, aprofundamento dos valores democráticos da vida social, e elevação material e espiritual da sociedade. Avaliação é produção de sentidos, prática social, portanto, intersubjetiva, relacional, aberta, polissêmica e carregada de valores, que põe em questão os significados dos fenômenos. Deve articular 
em um processo global e compreensivo os diversos aspectos constitutivos da educação, como os sentidos e valores da cognição, da autonomia moral, da vida social e pública e do conhecimento, que desenvolve a sociedade e eleva o espírito humano. Deve construir os campos sociais de discussão e valoração a respeito dos processos, contextos, produtos, objetivos, procedimentos, estruturas, causalidades, metas de superação, condições de produção das atividades educativas, sentidos e impactos na formação dos cidadãos e na construção da sociedade democrática. Então, não pode restringir-se a meros instrumentos estáticos, a só explicações do passado, nem há de ser simples controle e medida do já-feito. É processo dinâmico de comunicação, em que avaliadores e avaliados se constituem mutuamente. Assim, deve ser um patrimônio público a ser apropriado e exercido como instrumento de consolidação da educação como bem público; uma prática participativa e um empreendimento ético a serviço do fortalecimento da responsabilidade social da educação, entendida principalmente como o cumprimento científica e socialmente relevante dos processos de produção de conhecimentos e de formação de sujeitos com autonomia epistêmica, moral, social e política.

\section{Avaliação e finalidades da educação superior}

É importante deixar claramente estabelecido o foco principal deste texto. Como já anunciado no título, ele trata da avaliação educativa, não de outra de um outro qualquer ramo do conhecimento ou, ainda mais geralmente, da ação humana. $\mathrm{O}$ adjetivo que indica o foco destas reflexões tem aqui duas vias principais de sentidos. A primeira indica o objeto desta avaliação aqui tratada: a educação. Como a avaliação da educação tem que ser ela mesma educativa, a segunda diz respeito ao caráter formativo ou pedagógico do processo de avaliação. Toda prática humana, ainda quando se apresente como fatos, está inegavelmente carregada de valores. Como a educação é uma prática humana, a avaliação da educação é um processo impregnado de valores.

A educação superior cumpre atividades que carregam significados bastante complexos, relacionados com as questões epistêmicas, éticas, políticas, sociais, econômicas, culturais etc.. Entretanto, essa complexidade não deve ser vista como um empobrecimento por fragmentação e, sim, como possibilidade de múltiplas interatuações e relações.

A avaliação é um processo aberto à polissemia, mas não deve ser dispersiva. Por isso, a avaliação da educação superior não pode perder o seu foco principal, para também não perder sua eficácia social e pedagógica. Em outras palavras, 
sua referência central são os papéis essenciais da educação superior. Isto traz o sério problema de enfrentar uma definição ainda que rudimentar a respeito das finalidades e dos papéis essenciais da educação superior - tema também sempre carregado de ideologia e, então, de valores e interesses.

$\mathrm{O}$ que aqui estou assumindo como sendo a finalidade central da educação superior, ainda que não exclusiva e admitindo muitas limitações, é a formação para a vida em sociedade. Entendo que dentre todas as diversas tarefas que compete à educação superior desempenhar sobressai a de formar homens e mulheres para uma existência social mais digna, solidária, justa, material e espiritualmente mais elevada. No âmbito de sua atuação e de sua competência, de modo compartilhado entre as instituições, cabe à educação superior desenvolver, afirmar, consolidar ou mesmo construir a cidadania. Essa formação de cidadãos e consolidação da cidadania é, ao mesmo tempo, construção da sociedade democrática.

No fundo de todas as questões e com alguma dose de utopia, o que centralmente incumbe é a produção e a prática do direito e do dever de cada um e de todos se integrarem aos processos constitutivos da sociedade, tendo como parâmetros e orientação as leis e os projetos democráticos. A formação do cidadão, em sentido forte e amplo, aqui assumida como finalidade essencial da educação, é a construção e o desenvolvimento da dimensão psicossocial do sujeito. Esse sujeito que participa construtivamente da sociedade, com competência epistêmica e autonomia moral, é a garantia e a razão de ser da democracia, da vida democrático-republicana.

O princípio democrático-republicano, que diz respeito à construção em níveis cada vez mais elevados da sociedade, assegura e provê a existência das instituições educativas e delas exige o compromisso da qualidade científica e social e do interesse público. Disso infiro que compete à educação superior também trabalhar pelo fortalecimento da identidade nacional, pela formação da consciência de nação republicana e soberana. A educação superior é instrumento de aprofundamento e fortalecimento da autonomia pessoal, da emancipação do sujeito, mediante as relações com os valores, o conhecimento, a crítica, a reflexão, o exercício político da participação na vida da sociedade. O Estado deve garantir a proteção jurídica da esfera privada e dos processos democráticos (HABERMAS, 2003). A sociedade cria as instituições que a consolidam.

A responsabilidade social de uma instituição educativa diz respeito, então, centralmente, ao cumprimento, com qualidade e sentido social e público, de suas finalidades e seus objetivos essenciais: a formação (entendida como elevação humana em suas múltiplas dimensões), o desenvolvimento da sociedade 
democrática, o aprofundamento dos valores primordiais da vida em sociedade, dentre os quais a solidariedade, a liberdade, a justiça, os direitos públicos, o respeito à diversidade...

O trato com o conhecimento é um dos traços comuns e universais das instituições de educação superior. Produzir e transmitir conhecimentos é uma das funções essenciais, portanto, indescartáveis, de toda instituição educativa. A produção intelectual, as obras do espírito, são bem comum de uma nação e patrimônio da humanidade.

A produção e a socialização do conhecimento não são indissociados e, sim, constitutivos da formação humana. As instituições educativas são criadas pela sociedade para a produção do desenvolvimento da própria sociedade que as cria. Pelas atividades de produção e socialização do conhecimento, as instituições de educação superior cumprem a responsabilidade de responder com qualidade o mandato recebido da sociedade. Portanto, o principal conteúdo da responsabilidade social é responder com qualidade às exigências e às necessidades da sociedade, especialmente no que se refere à construção, à socialização e ao desenvolvimento do conhecimento e à prática social da formação humana.

Se educar é formar para a vida social, essa deve ser a matéria principal da avaliação. Em outras palavras, a avaliação deveria dirigir seu foco central à questão dos sentidos da formação dos cidadãos e do desenvolvimento da sociedade democrática e republicana. Essas ações de formação estão sempre mediatizadas pelos conhecimentos e impregnadas de valores.

A capacitação profissional é um dos aspectos importantes da formação da cidadania. Ela é uma das competências mais requisitadas da educação superior, ainda que não exclusiva desta. A formação, em sentido pleno, vai muito além da capacitação profissional. Mas, a capacitação profissional é um elemento imprescindível do desenvolvimento da vida social. Não deve tratar-se de mera capacitação técnica, de adesão acrítica às urgências do mercado, nem de adesão à economização da sociedade. Deve tratar-se da formação de profissionais competentes do ponto de vista técnico e operacional, porém, com profundo sentido ético, autonomia moral e consciência de que o conhecimento e a técnica são bens públicos. Sendo assim, por fazerem parte da formação cidadã de uma pessoa, devem ser elementos da construção da vontade e dos objetivos da sociedade democrática. Em outras palavras, não devem ser meros instrumentos do sucesso individual e de uma qualquer apropriação privada.

Eqüidade e justiça social são aspectos éticos e políticos que devem fazer parte dos sentidos das atividades formativas e cognitivas da educação. São 
dimensões essenciais da democracia. A justiça opera com o valor da inclusão e do respeito à diversidade. Inclusão não deve abafar a divergência, nem anular as diferenças e tampouco excluir aspectos fundamentais das culturas. A educação includente e justa não se refere apenas à ampliação das condições de acesso, mas também à apropriação democrática da formação e da ampliação de sentidos e possibilidades que ela libera.

\section{Avaliação é produção de sentidos}

A avaliação educativa é uma prática social, portanto, intersubjetiva, relacional, carregada de valores. Por tratar da educação, precisa ter compromisso com os princípios e valores que mais plenamente realizam as finalidades essenciais da vida humana. Deve ser uma reflexão radical sobre os significados dos fenômenos educativos; portanto, sobre os sentidos dos valores que estão sendo realizados na educação.

Por ser uma reflexão, não encerra, não conclui, não explica definitivamente, não fecha as significações. Não que não use a linguagem objetiva e não busque estabelecer conclusões. Porém, isso é apenas parte de um processo que, para além de explicar, busca pôr em questão e produzir significados. Aí, então, os sentidos são abertos, não concluídos, sempre relacionais e tendendo a novas implicações. Mais que explicar - que é uma maneira de concluir -, trata-se de implicar, abrir para renovadas significações, buscar a compreensão de conjunto através do relacionamento das partes, seja a respeito de uma dimensão específica (por exemplo, o ensino), seja sobre a totalidade institucional (a integração das atividades e estruturas de uma instituição) ou como visão de conjunto do sistema.

Duas perspectivas podem se combinar nesse processo explicativo-compreensivo: a visão comparativa, com seus vários recortes, e a perspectiva sistêmica. A reflexão também pode se realizar em vários níveis: individual (por exemplo, quando o professor reflete sobre sua própria prática) ou coletiva, quando a reflexão se socializa e envolve diversos conjuntos de atores institucionais. Seja como comparação entre as partes, seja uma visão de conjunto, tanto como reflexão individual ou como démarche coletiva, a avaliação deve se pôr em busca não apenas de explicação, mas sobretudo de compreensão e transformação de uma dada realidade.

Nisso reside o essencial da potencialidade formativa da avaliação: um processo aberto de comunicação entre sujeitos para compreender, valorar e transformar uma dada realidade. Aplicada à educação, esse processo de comunicação, que 
também é uma produção social de sentidos, fundamenta e reforça a capacidade de ação de indivíduos, de grupos sociais e do próprio Estado.

A educação é um fenômeno polissêmico, aberto, plurirreferencial. Tudo na educação tem interesse à avaliação, pois, cada um de seus aspectos sempre se remete a outros e não pode ser compreendido isoladamente. A instituição educativa transcende sua materialidade. Entretanto, sua transcendência imaterial só pode ser compreendida através das matérias que a constituem. Uma vez que essa materialidade é múltipla e dada a impossibilidade de avaliar tudo de uma só vez, é preciso priorizar o essencial. Mesmo que se dedique a aspectos particulares, a avaliação não pode perder seu foco, isto é, não pode deixar de visar os sentidos essenciais das estruturas, dos projetos, dos programas e das práticas educativas, entendendo sempre que tudo em educação deve estar referido à formação de seres humanos, tendo em vista a edificação de uma vida em sociedade mais elevada, justa e digna.

Educação é sempre um feixe de relações abertas. Por exemplo, é muito pouco importante simplesmente contabilizar o número de títulos e volumes, como se isso fosse avaliação plena de uma biblioteca, sem pôr em questão os significados desse espaço como lugar de formação, sem refletir sobre os sentidos do acervo relativamente ao ensino, à aprendizagem, aos processos de socialização e de vivência cultural, a uma filosofia educativa coerente com o avanço do conhecimento e com o desenvolvimento social etc..

É preciso buscar compreender o simbólico que funda a materialidade visível, quantificável e objetivamente descritível. Ao tratar de qualquer aspecto que medeia a vida de uma instituição, a avaliação não pode perder de vista que o seu objeto e o seu objetivo centrais são os fins da educação: a formação cidadã-profissional-ética-moral-política-técnica; a elevação e o desenvolvimento material, cultural, espiritual da sociedade; o avanço da ciência e o fortalecimento dos valores democráticos...

Em outras palavras, o essencial da avaliação é pôr em questão - isto é, refletir sobre - os sentidos e os valores do cumprimento do mandato social da educação que os atores, os segmentos institucionais, as instituições e o próprio sistema, conforme os casos, estão desempenhando.

\section{Avaliação: temas metacognitivos e socioprofissionais}

Nas avaliações que se realizam em diversos dos países mais industrializados e que tomam como objeto preferencial o estudante e as questões de aquisição de conhecimentos, é possível destacar duas grandes tendências, derivadas de duas 
correntes de pensamento. Uma delas, servindo-se dos avanços e do prestígio atual do cognitivismo e do interacionismo, tende a privilegiar o conhecimento dos processos de aprendizagem. De um ponto de vista mais centrado nos processos educativos e escolares internos à instituição, essa perspectiva de avaliação tende a conceder maior importância ao sujeito, em dois sentidos. Um desses aspectos refere-se aos processos de construção do pensamento do sujeito que aprende. A ênfase aqui não vem posta em exames ou testes estáticos, mas sobretudo em processos dinâmicos e instrumentos de solução de problemas.

Não só aspectos metacognitivos são levados em conta. O estudante é também um sujeito que participa conscientemente das atividades avaliativas e intervém no contexto social. Nesta perspectiva, a avaliação interage com os temas da aquisição de conhecimento, estratégias de aprendizagem, auto-avaliação, bem como com as perspectivas interacionistas que buscam superar os enfoques tradicionais, estáticos e somativos. Esses temas não surgem isolados. Junto com eles, entram em foco de consideração, também, as questões referentes ao trabalho docente, aos conteúdos e práticas de ensino e de investigação, enfim, diversas dimensões que de alguma forma interagem com os processos de construção, aquisição e socialização dos conhecimentos e dos valores.

A outra tendência, bastante recorrente nos países industrializados, remete a avaliação aos contextos socioprofissionais. Com forte ênfase em critérios econômicos, vocacionalistas e profissionais, esta perspectiva de avaliação se interessa especialmente pelos impactos da educação sobre a sociedade em termos econômicos e sociais, colocando em foco de análise questões como: eficácia e eficiência das instituições e dos sistemas educativos, relações entre educação e trabalho, adequação da formação profissional aos empregos, custo da educação, impactos das investigações na indústria, prestação de contas, responsabilidade fiscal, dados de empregabilidade e assim por diante.

Não há por que opor uma à outra dimensão. A educação nem se restringe a um mundo interno, que dissesse respeito apenas às atividades de ensino-aprendizagem e à vida "escolar" do estudante, por muito importante que isso seja, nem só se finaliza num mundo que lhe fosse exterior. Sendo essencialmente processo de formação, a educação tem a ver com os sentidos e valores da cognição, da autonomia moral, da vida social e pública. Essas duas tendências, uma que valoriza mais os processos educativos institucionalizados, outra que prioriza os produtos da educação em face do mundo econômico, devem ser vistas como co-essenciais e interdependentes. Ambas são dimensões indescartáveis da educação e não devem ser vítimas da lógica excludente. Coerentemente, a avaliação educativa deve articular em um processo global e compreensivo os 
diversos aspectos constitutivos do fenômeno complexo da educação, em suas dimensões de inseparável construção dos sujeitos e da sociedade.

\section{Avaliação: objetividade e subjetividade; avaliação como ético-epistemologia}

A avaliação é um processo social e intersubjetivo: uma relação interpessoal que questiona e produz os sentidos, as percepções e os saberes, que constituem os posicionamentos dos sujeitos ante uma realidade. A avaliação não é, portanto, isenta de valores. Não pode se resumir a mera aplicação e a análises frias de resultados de instrumentos tidos como objetivos e neutros, que pudessem engendrar juízos definitivos e inquestionáveis. Educação é um fenômeno social e relacional, prática humana de sujeitos sociais. A avaliação da educação não pode deixar de envolver os sujeitos concernidos pelas atividades educativas (professores, estudantes, técnicos, administradores, membros da sociedade, responsáveis pelas políticas públicas...). A avaliação se realiza numa comunidade de sujeitos que se relacionam, se comunicam com linguagens e objetivos compreensíveis e mais ou menos comuns, ainda que sempre necessitando de acordos nem sempre plenos, nem sempre duráveis. Segundo regras democráticas, a comunicação entre sujeitos autônomos resulta de processos de negociação pública de sentidos.

Em outras palavras, os processos avaliativos devem construir os campos sociais de discussão e valoração a respeito dos processos, contextos, produtos, objetivos, procedimentos, estruturas, causalidades, metas de superação dos problemas, enfim, sobre o que importa conhecer e o que precisa ser feito para melhorar o cumprimento das finalidades essenciais da educação. Fundamentalmente, são os sentidos da formação dos cidadãos e os impactos na construção da sociedade democrática que sobretudo devem estar em questão.

Esta perspectiva assume a subjetividade (intersubjetividade) da avaliação como dimensão essencial, em combinação com os aspectos objetivos da vida e das ciências "duras". As avaliações que se reduzem a testes objetivos ou a instrumentos semelhantes de paradigma exclusivamente objetivista, negam a subjetividade, afastando as reflexões e questionamentos partilhados dos avaliadores.

A avaliação referida a fenômenos humanos e, portanto, sociais, como é a educação, é necessariamente atividade complexa que precisa articular múltiplos referentes e perspectivas. Aos instrumentos e procedimentos das ciências "duras" devem articular-se as perspectivas e dimensões complexas de uma 
ético-epistemologia. A atividade avaliativa, social e intersubjetiva, enquanto processo de comunicação, deve ela também ser educativa, isto é, inserir-se dinamicamente nos processos mais amplos de formação e de transformação qualitativa dos atores, das instituições, do sistema educativo e da própria sociedade, através dos distintos meios de ensino, investigação, gestão, vinculação com o mundo econômico e social. Não como juízes exteriores e superiores, dotados de autoridade da determinação de julgamentos unilaterais e pretensamente neutros, mas como participantes dos processos formativos, os atores sociais da avaliação também se tornam mais responsáveis e comprometidos com a melhora da educação.

A avaliação institucional deve ser um empreendimento que busque compreender de modo articulado as diversas dimensões de uma instituição. É impossível abarcar a totalidade de uma só vez, mas deve haver um esforço metodológico de compreensão da globalidade feita através da articulação do entendimento das partes que vai sendo construído. Dizendo de outro modo: a inteligência das partes deve estar relacionada com a busca de compreensão do todo. Reciprocamente, a perspectiva da totalidade ajuda a melhor entender os sentidos das partes. As informações e os significados produzidos na atividade avaliativa devem ser a base para as ações de melhoria da realidade em foco.

A avaliação, portanto, não é somente um processo de inteligibilidade e produção de sentidos que se basta a si mesmo, mas é também processo de intervenção direta sobre as decisões, tanto nos níveis mais restritos e internos, quanto em termos de políticas públicas e de sistema. Assim concebida, a avaliação tem um sentido pedagógico de autonomização e de auto-regulação, e se relaciona com os projetos e processos institucionais de formação e gestão, ao mesmo tempo que é uma política pública inscrita nos programas do Estado.

A avaliação da educação superior pertence ao universo dos valores públicos. Como prática social de interesse e sentido públicos, para além do meramente técnico, tem um profundo significado ético. Dado seu caráter social e participativo, alimenta as qualidades comunicativas e de relações psicossociais e institucionais e inibe as práticas individualistas - competitivas.

\section{Avaliação estática e avaliação dinâmica; explicação e implicação}

A avaliação da educação precisa utilizar instrumentos de mensuração e procedimentos metodológicos estáticos. Entretanto, ela deve ser, em muitos casos, principalmente, dinâmica. Não deve se restringir às verificações e constatações 
a posteriori sobre produtos e ações já acabados, não deve se limitar a medidas fixas a respeito de quanto as normas e metas previamente e exteriormente estabelecidas teriam sido atingidas.

Muito comumente a avaliação é entendida e praticada só como um sistema de constatação ou de verificação da coerência/incoerência entre o ser (isto é, o realizado) e o dever ser (a norma, o ideal desejado). Dois critérios aí são tomados como importantes orientadores: a eficácia, que se refere à relação entre práticas e objetivos, e a eficiência, que diz respeito à coerência entre insumos e resultados.

Os instrumentos mais representativos desse enfoque, no que se refere às aquisições cognitivas por parte dos alunos, são as provas ou exames. É ainda muito freqüente tomar a avaliação por notas, exames, testes, controles, verificações, balanços. Entretanto, essas verificações, constatações e medidas são praticadas há alguns séculos e, ainda que cumpram bem alguns objetivos, não são suficientes para a compreensão de uma realidade tão complexa como a educação e, se exclusivos, tampouco são instrumentos capazes de levar a grandes transformações pedagógicas. Por isso, vêm de há muito tempo sofrendo críticas de importantes educadores. Para a reflexão que aqui está sendo desenvolvida, basta citar o que, já em 1988, dizia Helen Simons:

Ao focar a atenção exclusivamente na aquisição por parte do aluno de objetivos de aprendizagem predefinidos, o governo conserva uma visão da avaliação que já se encontrava ultrapassada nos anos 60 quando se reconhecia a necessidade de análises mais sofisticadas, que permitissem uma utilização da "avaliação como instrumento de inovação curricular”. (1993, p. 158).

Não se trata, então, de negar pura e simplesmente o valor das verificações e das medidas. O que é criticável é seu uso fechado e isolado. Nesse enfoque não costuma haver questionamento, muito pouco há de produção de sentidos sobre o referente e o referido, sobre a norma idealmente estabelecida e o realizado constatável e mensurável. Por isso, se os instrumentos e as práticas de medidas e meras constatações se bastam a si mesmas, não engendram questionamentos, não induzem reflexões e ações, ou o fazem muito pouco, então, esse tipo de procedimento avaliativo é conservador. Imprescindível é que essas técnicas propiciem reflexão, enriqueçam seus significados com o recurso a análises qualitativas, levem a questionamentos, isto é, façam parte de um conjunto de atividades epistêmicas e valorativas que produzam sentidos complexos e mobilizem os sujeitos para a tomada de decisões e de ações de melhoramento. 
A avaliação deve ser sobretudo um processo dinâmico que se inscreve no movimento dos demais processos educacionais, especialmente aqueles abertos à vida social e com caráter prospectivo. Deve refletir sobre processos, contextos, produtos, estruturas, causalidades e metas, pôr em questão os significados das idéias e das ações pedagógicas, dos valores das práticas e das políticas educativas e de seus efeitos na formação dos cidadãos e da sociedade, em vista de transformações e aprofundamentos necessários e socialmente desejados. Então, não há de restringir-se a meros instrumentos estáticos, a só explicações do passado, nem há de ser simples controle e medida do já-feito.

Quando exclusiva, a explicação desliga as relações, fragmenta, imobiliza. Entretanto essas constatações, verificações e medidas estáticas e temporais são muito úteis e mesmo imprescindíveis quando incorporadas a um processo longitudinal que liga a compreensão do já-realizado com a visão de um futuro que está sendo construído. Diferente da explicação, a implicação desdobra os sentidos, religando os elementos e restabelecendo as relações.

No caso específico do desempenho estudantil, a avaliação estática toma o estudante como um objeto a ser analisado, enquanto a avaliação dinâmica considera a historicidade da pessoa em formação. A avaliação dinâmica é um processo recorrente que busca entender as mudanças dos desempenhos do estudante, quando a ele se refere, ao longo do curso ou de um período determinado. Não se trata de fotografia ou medida da retenção de conteúdos num momento dado, mas sim de compreender as mudanças que vão ocorrendo ou os valores que vão se agregando ao longo do percurso. Esta mesma lógica serve para a avaliação de programas, cursos, instituições e assim por diante. Para além da fotografia estática, os movimentos.

A avaliação é plurirreferencial, múltipla, aberta, enquanto o controle é monorreferencial, único, fechado (ARDOINO; BERGER, 1989). A avaliação, à medida que se desenvolve, promove operações de questionamentos heterogêneos, isto é, produz sentidos sobre múltiplos e diferentes aspectos de uma realidade complexa - no caso, a educação.

Muitas são as dimensões da realidade educacional que podem ser selecionadas como objeto de uma avaliação: sistemas, instituições, cursos, estudantes, professores, relações sociais etc.. Creio ser possível destacar, dentre as práticas de avaliação mais recorrentes, duas perspectivas ou dimensões, ainda que elas não sejam as únicas importantes. Uma é a metacognitiva, que reflete e discute os processos de conhecimento e suas relações com os valores. Portanto, trata-se de uma dimensão claramente relacionada com a formação, em sentido amplo. A outra é a metaorganizacional, que tem como foco os aspectos organizacio- 
nais, estruturais e funcionais de uma instituição, de um programa ou mesmo de um sistema.

Essas duas dimensões não deveriam ser consideradas apartadas uma da outra. $\mathrm{O}$ conhecimento - vale dizer: os processos relacionais entre sujeitos e objetos - têm sua existência numa organização social nutrida de relações interpessoais. São essas relações intersubjetivas que constituem as organizações. É precisamente por meio dessas relações entre sujeitos que uma organização pode ultrapassar sua forma auto-suficiente e se torna uma instituição, isto é, incorpora à sua existência a construção de valores e objetivos sociais e públicos. São essas relações e esses sentidos que constituem o caráter essencialmente formativo de uma instituição social educativa. Assim, não se deve averiguar o desempenho estudantil sem levar em conta os processos relacionais da aprendizagem, nem se há de considerar as relações entre sujeitos e objetos e entre sujeitos e sujeitos sem religá-las às condições estruturais e estas à missão, à vocação, aos objetivos sociais. Por se tratar da questão humana, a educação é sempre plurirreferencial, e plurirreferencial há de ser também sua avaliação.

\section{Avaliação e controle; autonomia e regulação}

A avaliação não se confunde com o controle, mas este também é uma função da avaliação. $\mathrm{O}$ controle apresenta dois aspectos: um pertence à ordem jurídica e burocrática, ao campo das legislações e normas que regulam os procedimentos e asseguram a legitimação daqueles que as cumprem. Este aspecto poderia ser definido como um modelo que leva à regularização. Aí se trata de uma concepção estreita que se limita a realizar a conformidade com uma norma, de refazer algo para conformá-lo à "normação". A outra dimensão se refere à regulação, aqui entendida num sentido mais amplo, não meramente como conformidade, mas como dinâmica que utiliza todas as referências para avançar dentro dos limites superiores das possibilidades.

Este conceito de regulação dialoga com o de autonomia, isto é, com a promoção dos possíveis, a invenção dos caminhos e a projeção dos horizontes próprios. A autonomia não se confunde com a soberania, está sempre em relação com a alteridade e, portanto, com a heteronomia. Enquanto a regularização como mera conformação à norma e aos regulamentos é uma abdicação da autonomia, a regulação é um processo que faz intervir o diálogo ou a relação entre a autonomia, que é o exercício criativo e crítico da auto-regulação, e o quadro normativo externo, isto é, a heteronomia. A regulação, em muitos aspectos, estará em conformidade com a norma, porém, não há de se constrnger a um mero 
cumprimento acrítico e burocrático das determinações exteriores. A regulação deve guardar rica relação com a auto-regulação, isto é, com as oportunidades e possibilidades que se produzem no exercício criativo da autonomia.

Nos casos em que a avaliação se reduz a medida e a regularização ou a mero controle, no sentido de conformação à norma, ela é um instrumento de poder do professor, do administrador e de instâncias governamentais. Mas, diferentemente, se ela é um processo de regulação no sentido de que ajuda a compreender e melhorar a realização dos processos educativos, cognitivos, psicossociais, estruturais e organizacionais, então, ela é um patrimônio público, é um bem comum a serviço da formação dos indivíduos para a vida social, do desenvolvimento institucional e dos projetos do Estado.

\section{Avaliadores e avaliados: atores co-essenciais}

É preciso admitir com clareza: muitas das divergências sobre avaliação, ainda que pareçam ser de caráter técnico, são diferenças ideológicas, ou seja, de visão de sociedade. As pessoas têm distintos e contraditórios pontos de vista sobre avaliação porque têm distintas e muitas vezes contraditórias visões de mundo, incluindo concepções sobre educação.

Por isso mesmo a avaliação deve ser crível, porém não pode ter a pretensão de ser a demonstração conclusiva da verdade. Sua função não é revelar ou determinar a verdade, mas sim fundar as possibilidades para os processos sociais reflexivos que produzam os sentidos a respeito das ações, relações e produções educativas. Também por isso, nos processos avaliativos há que se considerar que avaliadores (ou mediadores da avaliação) e avaliados (que em muitos sentidos são também avaliadores, dado o sentido relacional e dialógico da avaliação) são atores co-essenciais. Constituem-se mutuamente de modo essencial no processo relacional da avaliação. Um não existiria sem o outro.

A relação que entre si estabelecem tem também duplo sentido: a avaliação é de um sobre o outro, mas, deve ser sobretudo uma interrogação de cada um sobre si mesmo em face do outro, na situação concreta de interrogação sobre os significados das práticas sociais. Neste sentido, a avaliação é também um processo de formação, de apropriação dos sentidos das experiências, das situações e dos projetos de vida. Ela está atenta às interrelações. Não separa o mundo objetivo e as visões subjetivas, não opõe os enfoques quantitativos e os qualitativos, nem separa os fatos dos valores.

A avaliação é trabalho de implicação, para além da explicação. Isso significa que ela é um processo de articulação dos elementos heterogêneos, das relações 
e dos sentidos abertos e muitas vezes contraditórios. O controle separa os elos do que seria uma inteligibilidade integrada, rompe as conexões e as relações para explicar o elemento fragmentado e isolado, com propósitos de demonstração conclusiva e não de abertura a novos significados.

Este enfoque de avaliação tem a ver tanto com as dimensões de formação dos atores (estudantes, professores, técnicos, gestores etc.) nos âmbitos institucionais, quanto com a consolidação de um sistema de educação superior com sentido de estratégia nacional. Sistema remete a idéias, concepções e práticas interdependentes e correlacionadas. A idéia forte a fundar toda essa perspectiva é que educação é bem público, é bem comum: deve ser promovida com a intenção de beneficiar o conjunto da população, os conhecimentos e a formação devem se realizar na perspectiva dos valores mais caros a uma sociedade democrática e devem ser apropriados democraticamente.

"A educação tem como função essencial a formação de sujeitos autônomos entendida como núcleo da vida social” (DIAS SOBRINHO, 2005, p. 236). Daí que a avaliação da educação também deve ser um patrimônio público a ser apropriado e exercido como instrumento de consolidação da educação como bem comum, seja ela provida pelo estado ou por iniciativas privadas. Então, deve ser uma prática participativa e um empreendimento ético a serviço do fortalecimento da responsabilidade social da educação, entendida esta principalmente como o cumprimento científica e socialmente relevante dos processos de produção de conhecimentos e de formação de sujeitos com autonomia epistêmica, moral, social e política.

Dito isso, é possível encerrar retomando a idéia inaugural deste texto: a avaliação deve estar focada na questão dos sentidos do cumprimento por parte da educação superior, seja nos níveis internos de cada curso e instituição ou nas escalas mais amplas dos sistemas, daquilo que essencialmente lhe determina a sociedade: a formação de cidadãos, o aprofundamento dos valores democráticos da vida social, a elevação material e espiritual da sociedade. "Em conseqüência, desenvolve-se uma forte sinergia entre avaliação e valores democráticos e republicanos, bem como políticas que neles se fundamentam, tais como o conhecimento para a emancipação, a justiça social, a inclusão." (DIAS SOBRINHO, 2003, p. 120). 


\section{Referências}

ARDOINO, Jacques; BERGER Guy. D'une évaluation en miettes à une évaluation en actes. Le cas des Universités. Paris: ANDSHA/Matrice, 1989.

DIAS SOBRINHO, José. O sentido ético da avaliação. In: APPEL, Emmanuel (Org.). A Universidade na encruzilhada. Universidade: por que e como reformar?, UNESCO/MEC: Brasília, 2003.

DIAS SOBRINHO, José. Dilemas da educação superior no mundo globalizado. Sociedade do conhecimento ou economia do conhecimento?, São Paulo: Casa do Psicólogo, 2005.

HABERMAS, Jürgen. Au-delà du libéralisme et du républicanisme, la démocratie délibérative. In: Raison Publique. Délibération et gouvernance: l'illusion démocratique?. Bayard: Paris, 2003.

SIMONS, Helen. Avaliação e reforma das escolas. In: ESTRELA, A.; NÓVOA, A. (Org.). Avaliações em educação: novas perspectivas. Porto: Porto, 1993. 